\title{
Maternal outcomes of the childbirth among primiparous teenagers in South Kivu, RD Congo
}

\author{
Ntamulenga Innocent $^{1 *}$, Mukanire Ntakwinja ${ }^{1}$, Imani Prince ${ }^{1}$, Kasereka Kikwaya ${ }^{1}$, \\ Nyakio Olivier ${ }^{1}$, Mukwege Denis ${ }^{1}$, Sengeyi Dieudonné
}

\begin{abstract}
${ }^{1}$ Department of Gynecology and Obstetrics, Evangelic University, Democratic Republic of the Congo
${ }^{2}$ Department of Gynecology and Obstetrics, University of Kinsasha, Democratic Republic of the Congo
\end{abstract}

Received: 19 December 2018

Accepted: 11 January 2019

\author{
*Correspondence: \\ Dr. Ntamulenga Innocent, \\ E-mail: ntamulengainnocent@gmail.com
}

Copyright: (c) the author(s), publisher and licensee Medip Academy. This is an open-access article distributed under the terms of the Creative Commons Attribution Non-Commercial License, which permits unrestricted non-commercial use, distribution, and reproduction in any medium, provided the original work is properly cited.

\begin{abstract}
Background: Adolescent births remain at high risk. The aim of this study was to determine the maternal prognosis of births among primiparous teenagers in South Kivu.

Methods: A case-control study of 250 primiparous teenagers (cases) and another group of 500 primiparous adults aged 20-34 years (control) was performed in 4 General Reference Hospitals of South Kivu in Republic Democratic Congo. The study period was from January to December 2017. A survey sheet was used to collect the data. The analysis were performed using SPSS 22.0 and EPIINFO version 7.2.2.6.

Results: Out of a total of 8490 deliveries recorded at the 4 General Reference Hospitals in South Kivu in 2017, authors recorded 250 deliveries of primiparous teenagers, or $2.9 \%$. The maternal prognosis of adolescent deliveries was more marked by a high rate of caesarean section $(\mathrm{OR}=13.5)$, the presence of complications $(\mathrm{OR}=7.37)$, prolonged labor $(\mathrm{OR}=4.51)$, lesions soft tissues $(\mathrm{OR}=3.92)$, intraoperative bleeding $(\mathrm{OR}=3.26)$ and fever by puerperal infection $(\mathrm{OR}=2.13)$.

Conclusions: The frequency of childbirth among primiparous teenagers and maternal-neonatal prognosis has been determined and is of concern. The prevention of adolescent obstetric complications includes the respect for the legal age of marriage, adequate antenatal care and childbirth in a specialized hospital setting.
\end{abstract}

Keywords: Childbirth, Maternal prognosis, Primiparous, Teenagers

\section{INTRODUCTION}

According to WHO, every year, there are about 16 million adolescent girls aged 15-19 who give birth, which accounts for $11 \%$ of all deliveries worldwide. ${ }^{1}$ Adolescent pregnancy has become a major public health problem in both developing and industrialized countries, with significant increases in fertility rates below the age of 18 , and significant medical and psychological risks and social problems to which both mother and child are exposed. $^{2}$ The situation worsens when the young woman finds herself in an environment dominated by immaturity, irresponsibility, poor socio-economic conditions and sometimes the illegitimacy of pregnancy, from which the foeto-maternal prognosis becomes clouded. ${ }^{3}$ Two million girls under the age of 15 give birth each year to the world, and half of all teenage births occur in seven countries, including Bangladesh, Brazil, the United States of America, Ethiopia, the United States, and the United States. India, Nigeria and the Democratic Republic of Congo. ${ }^{4}$ In the DRC, data on the frequency of deliveries among primiparous teenagers are not sufficiently documented. In South Kivu, the extent of adolescent 
deliveries is not sufficiently documented, except for a study conducted by Lushenga in Panzi in 2013 which showed that pregnancies among women under 18 years of age played a significant role with $4.9 \%$. Most of these women under 18 come from urban areas with $74.7 \%$. The majority of deliveries were eutocic [75.3\%]. Most newborns had a weight greater than or equal to $2500 \mathrm{~g}$ [91.8\%] and APGAR greater than or equal to 7 [89.9\%], the most common dystocia were pelvic anomalies. ${ }^{5}$ In view of the above, authors ask themselves the following question: what are the maternal complications of teenage deliveries in South Kivu? The aim of present study was to contribute to the improvement of maternal-neonatal complications of deliveries in primiparous teenagers in South Kivu.

\section{METHODS}

This study is of the control type, involving 250 adolescent female deliveries who were cases and 500 adults (controls), two adult patients who were followed by an adolescent were maintained. Over a 12-month period from January 1 to December 31, 2017. Authors included all primiparous girls aged 13 to 19 who gave birth in the Gynecology and Obstetrics department of the four selected hospitals during the study period.

The dependent variable of this study was maternal complications. The independent variables are: The sociodemographic characteristics of the respondents, pathologies that occurred during the pregnancy, report of the operation, the postoperative consequences. For the selection of topics included in this study, authors used the non-probability sampling technique of convenience.

\section{Statistical analysis}

The statistical tests were done with SPSS software version 22 and EPIINFO 7 in a complementary way using the Chi2 test $(\mathrm{P}<0.05)$ for qualitative or Fisher variables when their application conditions were met. For the comparison of the means, authors used Student's T test and the intensity of the association was made thanks to the Odds Ratio association measure and its 95\% confidence interval.

This study was authorized and approved by the provincial ethics commission, respecting the anonymity and confidentiality of the information collected.

\section{RESULTS}

From a total of 8490 deliveries recorded in the 4 General Reference Hospitals of South Kivu during the period from 1 January to 31 December 2017, authors recorded 250 deliveries in women under 20, a prevalence $2.9 \%$. (ZS IBANDA, KABARE, WALUNGU and NYATENDE, 2017). From this table 1, authors note that the average age of teenagers is $17.62 \pm 1.07$ years versus $26.34 \pm 4.10$ years in adults, note that this difference is statistically significant. Childbirth among teenagers were unprofessional $(87.6 \%)$ were more without a job function while $(30 \%)$ of adults were employed in the public service, with a statistically significant difference ( $p$ $<0.000)$. For marital status, $(19.6 \%)$ teenagers were single. Authors also note a positive statistical association between occupation, marital status, and respondent groups. (P <0.0001). With OR (IC) $=7.88$ (4.18-15.06) (Table 1).

Table 1: Sociodemographic characteristics of study population in relationship of age.

\begin{tabular}{|c|c|c|c|c|c|}
\hline Parameters & n $(\%)$ & Teenagers $<20$ years $n(\%)$ & Adults $20-34$ years n (\%) & OR $(95 \%$ IC) & $\mathbf{P}$ \\
\hline Age in years & & $17.62 \pm 1.07$ ANS & $26.34 \pm 4.10 \mathrm{ANS}$ & & 0.000 \\
\hline \multicolumn{6}{|c|}{ Professional status } \\
\hline Unemployed & $635(84.7)$ & $219(34.5)$ & $416(655)$ & & \\
\hline Traders & $39(5.2)$ & $6(15.4)$ & $33(84.6)$ & $3.94(1.65-9.40)$ & 0.000 \\
\hline Braiding & $12(1.6)$ & $0(0.0)$ & $12(100.0)$ & & \\
\hline \multicolumn{6}{|c|}{ Marital status } \\
\hline Married & $686(91.5)$ & $201(30.6)$ & $485(69.4)$ & 1 & \\
\hline Single & $64(8.5)$ & $49(76.5)$ & $15(23.5)$ & $7.88(4.18-15.06)$ & 0.000 \\
\hline
\end{tabular}

In both groups, several incision techniques were used, including the Adult Umbilical Incision (32.8\%) and the Joël Cohen incision in the adolescent girl (35.7\%). Cephalic extraction was the winner with $(89.3 \%)$ adolescent girls and artificial delivery. Among the complications during caesarean section, teenagers had more abundant intraoperative bleeding than adults with ( $\mathrm{p}$ $<0.0001$ ) (Table 2). With regard to vaginal complications, the results in Table 3 show that $14(20.5 \%)$ of adolescent deliveries were more likely to experience tears in the cervix, perineum, and endometritis than adults.

There was a statistically significant difference between adolescent girls and adults with respect to postoperative complications $(p=0.008)$. Adolescent girls were more likely to develop postoperative complications, including eclampsia, haemorrhage, malaria, and other deliveries (Table 3). 
The maternal prognosis among teenagers was more marked by a high rate of caesarean section $(\mathrm{OR}=13.5)$, the presence of complications $(\mathrm{OR}=7.37)$, a prolonged labor $(\mathrm{OR}=4.51)$, lesions of the parts marrows $(\mathrm{OR}=3.92)$, intraoperative bleeding $(\mathrm{OR}=3.26)$ and fever $(\mathrm{OR}=2.13)$ with $\mathrm{p}<0.05$.
In multivariate analysis, teenagers mothers were more likely to have complications and peroperative bleeding compared to women aged 20-34 years with $\mathrm{p}<0.05$ (Table 4).

Table 2: Surgical report of respondents according to age groups

\begin{tabular}{|c|c|c|c|c|c|}
\hline Parametres & n $(\%)$ & Teenagers $\mathbf{n}(\%)$ & Adults n (\%) & OR $(95 \%$ IC $)$ & $\mathbf{P}$ \\
\hline \multicolumn{6}{|l|}{ Delayed intervention } \\
\hline Yes & $28(15.5)$ & $4(7.1)$ & $24(19.2)$ & 1 & \\
\hline No & $153(84.4)$ & $51(92.9)$ & $102(78.8)$ & $0.33(0.09-1.09)$ & 0.070 \\
\hline \multicolumn{6}{|c|}{ Cutaneous incision technique } \\
\hline IMSO & $53(29.3)$ & $12(21.4)$ & $41(32.8)$ & 1 & \\
\hline Pfanennstiel incision & $78(43.1)$ & $24(42.9)$ & $54(43.2)$ & $0.66(0.27-1.58)$ & \\
\hline \multicolumn{6}{|l|}{ Extraction } \\
\hline Cephalic & $152(84.0)$ & $50(89.3)$ & $102(81.6)$ & 1 & \\
\hline Breech & $29(16.0)$ & $6(10.7)$ & $23(18.4)$ & $1.88(0.67-5.53)$ & 0.27 \\
\hline \multicolumn{6}{|c|}{ Anesthesic complication } \\
\hline Yes & $170(94.0)$ & $56(100.0)$ & $114(91.2)$ & & \\
\hline No & $11(6.0)$ & $0(0.0)$ & $11(8.8)$ & & $\mathbf{0 , 0 1 8}$ \\
\hline \multicolumn{6}{|c|}{ Intraoperative bleeding } \\
\hline Normal ( $\leq 500 \mathrm{cc})$ & $100(55.6)$ & $44(78.6)$ & $56(44.8)$ & $0.72(0.26-1.95)$ & 0.62 \\
\hline Abundant $(>500 \mathrm{cc})$ & $81(44.8)$ & $12(21.4)$ & $69(55.2)$ & 1 & \\
\hline \multicolumn{6}{|c|}{ Intraoperative accidents } \\
\hline Yes & $13(7.2)$ & $0(0.0)$ & $13(10.4)$ & 1 & \\
\hline No & $168(92.8)$ & $56(100.0)$ & $112(89.6)$ & $000(0.00-0.82)$ & 0.010 \\
\hline
\end{tabular}

Table 3: Distribution of our respondents according to the complications.

\begin{tabular}{|l|l|l|l|l|l|}
\hline Parametres & N & Teenagers n (\%) & Adults n (\%) & OR $(95 \%$ IC) & P \\
\hline Complications by normal childbirth (102) & & & & \\
\hline Cervical tears & $22(21.5)$ & $14(20.5)$ & $8(23.5)$ & 1 & \\
\hline Perineal tears & $30(29.4)$ & $20(29.4)$ & $10(29.4)$ & $0.88(0.24-3.23)$ & 0.039 \\
\hline Endometritis & $50(49.1)$ & $34(50.1)$ & $16(47.1)$ & $0.82(0.25-2.68)$ & 0.920 \\
\hline Postoperative complications (n=138) & & & & \\
\hline Heamorrhage & $20(14.4)$ & $14(15.9)$ & $6(13.6)$ & \\
\hline Pelviperitonitis & $10(7.8)$ & $6(6.8)$ & $4(9.0)$ & \\
\hline Endometritis & $30(21.7)$ & $18(20.4)$ & $12(27.2)$ & \\
\hline Thrombophlebitis & $6(4.3)$ & $2(2.2)$ & $4(9.0)$ & \\
\hline Malaria & $38(27.5)$ & $28(31.8)$ & $10(22.7)$ & \\
\hline Eclampsia & $10(7.2)$ & $8(9.0)$ & $2(4.5)$ & \\
\hline Pariatal infection & $18(13.0)$ & $12(13.6)$ & $6(13.6)$ & \\
\hline
\end{tabular}

Table 4: Distribution of our respondents according to maternal prognosis.

\begin{tabular}{|l|l|l|l|l|l|l|}
\hline \multirow{2}{*}{ Parameters } & \multicolumn{2}{l}{ Teenagers } & \multicolumn{2}{l|}{ Adults } & OR brut & ORa $(95 \%$ CI) \\
\hline Presence of complications & N & \% & N & \% & $(95 \%$ IC) & \\
\hline caesarean & 67 & 86.0 & 8 & 14.0 & $7.37(3.41-15.9)$ & $5.85(2.54-13.4)$ \\
\hline Vicious presentation & 8 & 55.6 & 53 & 44.4 & $13.5(52.8-34.3)$ & $9.92(3.78-25.9)$ \\
\hline Lesions of the soft parts & 15 & 74.4 & 21 & 65.6 & $0.82(0.35-1.94)$ & - \\
\hline Haemorrhage & 7 & 70.0 & 4 & 21.1 & $3.92(1.28-11.9)$ & $3.54(0.89-14.0)$ \\
\hline Fever & 7 & 87.5 & 1 & 12.5 & $2.13(1.01-4.14)$ & $2.04(0.99-5.06)$ \\
\hline Prolonged labour & 13 & 81.3 & 3 & 18.8 & $4.51(1.27-16.0)$ & $3.31(0.84-12.9)$ \\
\hline
\end{tabular}




\section{DISCUSSION}

Present study identified two types of important findings: maternal prognosis and neonatal prognosis of adolescent deliveries. The maternal prognosis among adolescents was more marked by a high rate of caesarean section $(\mathrm{OR}=13.5)$, the presence of complications $(\mathrm{OR}=7.37)$, prolonged labor $(\mathrm{OR}=4.51)$, lesions of the parts marrows $(\mathrm{OR}=3.92)$, intraoperative bleeding $(\mathrm{OR}=3.26)$ and fever $(\mathrm{OR}=2.13)$ with $\mathrm{p}<0.05$.

With regard to caesarean section, other authors around the world have found results similar to ours including Evrim who found during her a study conducted in Turkey in 2017 found a high rate of caesarean sectional. ${ }^{5}$ Luhete in the city of Lubumbashi and Mumba et al in the city of Mbuji-Mayi, these authors explain this high rate by pathophysiological mechanisms including the obstetric basin and the genital sector would be growing, which would lead to the increased risk of prolonged labor, the use of episiotomy, and in the worst case, more Caesarean sections are expected to be performed as documented by other authors such as Jolly in New Zealand and Smith in Scotland. ${ }^{6-9}$

Our results corroborate those of Evrim, who found during her study in Turkey in 2017 on maternal-fetal prognostic factors of adolescent deliveries, that adolescent girls had a high rate of premature deliveries, premature rupture of membranes and admission to a neonatal unit with a significant difference $(\mathrm{p}<0.001){ }^{5}$

Furthermore, at the end of present study, Authors noted the presence of complications in the course of teenage delivery compared to adults and the main complications recorded vaginally were endometritis, tearing of the perineum and cervical tear with a statistically significant difference $(\mathrm{p}=0.039)$, whereas in the postoperative period, Authors recorded the following complications: eclampsia, malaria, haemorrhage and parietal infection with $\mathrm{p}=0.008$.

In our series, eclampsia is the leading teenage postoperative complication. This association between eclampsia and adolescent girls has also been found in other studies. ${ }^{10}$ It is well recognized that arterial hypertension is more common in very young women and the main factors of pathological entities of vasculo-renal syndrome are biological and endocrine immaturity, primigality and lack of prenatal follow-up. ${ }^{8,9}$ This situation therefore affects the neonatal prognosis. The prevention strategies of vascular-renal syndromes involve interventions that go in the direction of fighting against these various identified risk factors and in the case where actions prove difficult, special attention will be paid to the gravida

Authors also noticed that women under the age of 20 had more postoperative malaria than adults. The only plausible explanation in this case is the low attendance at antenatal clinics where preventive interventions such as intermittent prophylaxis against malaria are provided. The same observation was made by Rogerson et al. who had found that age greater than 20 appears to be a protective factor against malaria infection during pregnancy, thus, the apparent protection in primiparous women would be related to the older age in the adult group; this constant is explained by the fact that in the endemic environment immunity from premunition increases with age. ${ }^{11}$

Haemorrhage occurred in 3rd position as a complication with a high frequency in women under 20 years. Our results are in agreement with those of Leppälahti and Mahavarkar who find a high risk of developing anemia during childbirth in the adolescent group. This could be explained by the global immaturity of the genitals of women under 20 years of age. The other variables of the maternal prognosis, in particular the vicious presentation, can easily be explained by the immaturity of the maternal pelvis linked to the woman'svery age, which can in turn lead to a premature rupture of the membranes. ${ }^{12,13}$

\section{CONCLUSION}

Authors have identified that teenager childbirth is at high risk. The frequency of childbirth among primiparous teenagers was $2.9 \%$ in our environment. The maternal prognosis following childbirth among primiparous teenager was characterized by the high risk of cesarean section, the high risk of complications including eclampsia, puerperal infection and maternal hemorrhage.

\section{ACKNOWLEDGMENTS}

Authors would like to thank Mr. Philemon Mulongo for his help in submitting this article. Authors are also grateful to the all the medical directors of the four hospitals for allowing them to freely collect the data of the present study.

Funding: No funding sources

Conflict of interest: None declared

Ethical approval: The study was approved by the Institutional Ethics Committee

\section{REFERENCES}

1. Ugianskiene A, Ledertoug S, Murrekilde P, Bor IP. Teenage pregnancies: Obstetric and neonatal outcomes at a Danish Regional Hospital. J Women's Health Care. 2015;4:7.

2. Abbas AM, Ali SS, Ali MK, Fouly H, Altraigey A. The maternal and neonatal outcomes of teenage pregnancy in a tertiary university hospital in Egypt. Proceed Obstet Gynecol. 2017;7(3):1-10.

3. Goossens G, Kadji C, Delvenne V. Teenage pregnancy: a psychopathological risk for mothers and babies? Psychiatr Danub. 2015;27(1):S499-503. 
4. Braine T. Pregnancy in adolescence: a complex cultural problem. Bull OMS. 2009;87(6):405-84.

5. Ergen EB, Yayla CA, Sanverdi I, Ozkaya E, Kilicci C, Kocakusak CK. Maternal-fetal outcome associated with adolescent pregnancy in a tertiary referral center: a cross-sectional study. Ginekologia Polska. 2017;88(12):674-8.

6. Luhete PK, Mukuku O, Tambwe AM, Kayamba PK. Study of maternal and perinatal prognosis for vaginal delivery in adolescent girls in Lubumbashi, Democratic Republic of the Congo. Pan Afr Med J. 2017;26:182.

7. Mumba MA, Kadima MC, Bukasa M, Mikenji J. Pronostic maternal childbirth at extreme age in Mbujimayi. Rev Med Gd Lakes. 2014;3(2):170-191.

8. Jolly MC, Sebire N, Harris J, Robinson HS, Regan L. Obstetric risk of pregnancy in women less than 18 years old. Obstet Gynecol 2000; 96(6):962-66.

9. Smith GC, Pell JP. Teenage pregnancy and risk of adverse perinatal outcomes associated with first and second births population based retrospective cohort study. BMJ. 2001;323(7311):476.

10. Tebeu PM, Halle G, Lemogoum D, Simo Wambo AG, Kengne Fosso G, Fomulu JN. Risk factors for eclampsia among patients with pregnancy-related hypertension at Maroua Regional Hospital, Cameroon. Int J Gynaecol Obstet. 2012;118(3):2546.

11. Rogerson SJ, Chaluluka E, Kanjala M, Mkundika P, Mhango C, Molyneux ME. Intermittent sulfadoxinepyrimethamine in pregnancy: effectiveness against malaria morbidity in Blantyre, Malawi, in 19971999. Transac Royal Society Trop Med Hyg. 2000;94(5):549-53.

12. Leppälahti S, Gissler M, Mentula M, Heikinheimo O. Is teenage pregnancy an obstetric risk in a welfare society? A population based study in Finland, from 2006 to 2011. BMJ Open. 2013;3(8):e003225.

13. Ministry of Planning and Follow-up of the Implementation of the Modernity Revolution (MPSMRM), Ministry of Public Health (MSP) and ICF International, 2014. Demographic and Health Survey in the Democratic Republic of Congo 20132014. Rockville, Maryland.

Cite this article as: Innocent $\mathrm{N}$, Ntakwinja $\mathrm{M}$, Prince I, Kikwaya K, Olivier N, Denis M et al. Maternal outcomes of the childbirth among primiparous teenagers in South Kivu, RD Congo. Int J Reprod Contracept Obstet Gynecol 2019;8:797801. 